\title{
HEARABLES: ELEARNING IN THE WORKPLACE
}

\author{
Rory McGreal, Athabasca University, Canada
}

\section{Introduction}

Hearables, a term first coined by Hunn (2014), are wireless smart micro-computers with artificial intelligence that incorporate both speakers and microphones. They fit in the ears and can connect to the internet and to other devices; they are designed to be worn daily. These devices, such as the Bragi Dash, Vinci and Bose Hearphone are now appearing on the market, which is expected to exceed $\$ 40$ billion in the USA by 2020 (Omnicom, 2018). Hearables are not headphones, nor hearing aids, nor ear plugs, although they could take on the affordances of any of these devices (Banks, 2018). Headphones are designed for listening to music. Hearing aids are designed as an aid for the hearing impaired. Ear plugs reduce unwanted sounds by cancelling noise. Hearables offer comparable features and additionally provide users with a microphone and connectivity to the internet supporting telephony and personal digital assistant (PDA) services (Computational Thinkers, n.d.). Prior to 2017, in the USA, such devices required the approval of the Food and Drug Administration. This approval is no longer required for hearables, as they are no longer considered to be medical hearing aids (Over the Counter Hearing Aid Act, 2017). This paves the way for the expansion in the market of significantly lower-priced hearables, undercutting the expensively-priced hearing aid market.

\section{Hearables for Workplace eLearning}

Hearables stream music or audio content wirelessly using Bluetooth. Phone calls can be taken hands-free. Noises can be filtered out and speech amplified and filtered. And, with augmented audio, hearables can transform the user experience with sound controls and special effects (Traynor, 2017).

Hearables can be also used to simply enhance the listening experience. Hunn (2014) refers to them as the "new wearables". As such, they represent a subset of wearable computers, which now includes wrist bands like Fitbit, eye wear like Google Glass, intelligent garments like CruchWear, or shoes like Nike+. Hearables must be distinguished from audibles like Amazon's Alexa, Apple's Siri, Microsoft's Cortana and Google Assistant. The difference is that of mobility - hearables can go anywhere with the user, whereas audibles are place-based.

To date, hearable companies have focused on either music, because of its wide popularity or the health and sports markets because of their devices' ability to monitor and track body performance such as the heart-rate, energy, oxygen saturation, etc. or physical activity such 
as, speed, time, counting steps, etc. The ear is one of the best places to accurately measure biometrics and physical activities. In addition, the newest hearables can now provide asneeded advice on request by users. A PDA can instantly access various web applications, such as news and weather reports or route planning. Another form of specialised hearables are the earphone language translators such as Google Pixel Buds and Waverly Labs Pilot. This feature and others open up the possibility of taking full advantage of these devices to support mobile learning and other forms of both traditional and distance education.

Distance learning has been evolving at a rapid pace since the arrival of the ubiquitous internet at the end of the last century. The old correspondence school model based on the postal system was ported to the Internet, increasing response times. Then the affordances of the internet allowed for greater interactivity, at the beginning through simple email, then with social networking, audio and video conferencing and Voice-Over-IP using desktop computers. Mobile devices including smart phones, tablets and laptops are now ubiquitous. They allow users to access the internet from wherever they are. More people today access the Internet using these mobile devices than by any other means (ITU, 2017). Students are taking full advantage by accessing their lessons online. Both formal and informal learners are also accessing instructional videos, audio books and manuals, podcasts, personal recordings, and other training, explaining, and skill enhancing websites.

More recently, place-based audible technologies have demonstrated the convenience of using these PDAs in the home and office. Their capability for intelligent voice recognition (IVR) and natural language understanding (NLU) enables these devices to serve as powerful interactive digital advisers. In fact, these interactions could become the principal means for spontaneous queries (Burrows, 2018). This has opened the possibilities for using IVR and NLU to support learning.

Place-based audibles can be used in the administration of education. Ellis (2018), reported on a campus-wide distribution of Echo Dot audible devices with Alexa to all the students. She noted how the devices are being used to relay information from the institution to students, alerting them to deadlines or dates on the academic calendar, as well as faculty office hours or even the cafeteria menus. She also noted that students were using their devices as PDAs advising them on a wide range of campus and other activities. Hearables could be used in a similar manner, while allowing students more flexibility, because they can remain connected wherever they are, and so not be confined to their residences in accessing Alexa and the broader internet.

Now, with the availability of hearable devices, one can begin to explore in what ways, they can be advantageous. Hearing is a private and personal activity. This should be kept in mind when designing applications and tasks. Perhaps the most significant advantage for hearables comes with their ability to provide features that exceed the capabilities of the basic hearing aid. Hearables can augment the ability of the user to hear and discriminate sounds, helping the users to focus on those sounds that are the most important - super hearing. For example, an emergency respondent could be alerted to the slightest sound in a burning building. 
Hearables also facilitate switching from one function to another seamlessly, while providing useful advice as needed. With the growth of augmented reality and other forms of multimedia, users will need to have audio input, so hearables could become essential in these alternative environments. As we know from the user experience with home-based audible devices, the voice interactions can be natural and personal. In a mobile environment, perhaps the most important application will be the ability of users to instantly access the information they need in real time; in the workplace, the added advantage of being hands-free cannot be underestimated.

Brown (2016) noted several advantages of hearables. Notably, they can be used for most, if not all, of the traditional sound-related applications, such as listening to music, and mitigating hearing loss. In addition, hearables can augment sounds; this improves hearing above the norm by empowering users to apply selective noise cancellation (removing extraneous noise) and focus on specific sounds, such as a baby crying. Instant replay and recording of words is also possible, so users can check for understanding or file a recording as a record of an agreement. Another important feature is the ability to instantly translate between languages. The biometric capabilities allow for measuring health and fitness variables, providing users with a health record and even sound an alert for a sudden medical emergency. Biometrics can also be used for security authentication.

For educators, the information/communications functions can be effectively exploited. These features support the delivery of lectures, educational podcasts, notifications, and reminders through a wide variety of applications, while supporting interactivity. Intelligent hearables can determine the context and choose the right time and place to deliver the best content. These PDAs can become one of the principal ways we interact in learning.

There are significant challenges in using hearable devices. There are major concerns related to the social acceptability of people talking out loud in a public space or office. There has also been a stigma attached to hearing aids, with many people considering them to be unfashionable and only for the elderly. Manufacturers are addressing the stigma by designing devices that are unobtrusive, sitting securely inside the ear. Hunn (2015) suggests that the comfort of these new lightweight devices will help to destigmatise their use. Of course, another approach is to create more fashionable devices - the earrings of the future (Lumen, 2018).

\section{Just-in-time learning/Context-based learning}

With ubiquitous access to the internet and its plethora of educational/training content, hearables are well-placed to play a significant, if not the most important role in supporting Just-in-Time Learning. Using hearables, learners can now access important training whenever and wherever it is needed. In the mobile workplace, using hearables, continuous training can be integrated into every workday. For example, when faced with faulty new machinery, a machinist can access instructions on how to fix the problem or even contact the manufacturer directly using hearables, while leaving his hands-free to follow instructions in 
real time. Sales people, while driving on their way to meet clients can use their hearables to brush up their knowledge of the customer, of their product line or even their presentation skills. To facilitate these training opportunities, designers should organize the content into bite-sized chunks as there are few workers who can spend an hour or even a half hour away from the job. People learn faster when the learning is immediately needed and in a meaningful context.

\section{Self-directed learning}

Hearables can play a key role in independent study. They can serve to detach learners from formal institutional education, expanding the variety of places, times and ways their learning can be supported. They can serve as an important tool, helping a learner to become more directed, autonomous, motivated, organized and disciplined. A PDA can help with identifying the learning resources needed, providing constructive feedback, monitoring progress, and aiding in the process of self-assessment and setting personal goals. In addition, hearables can be used to help structure study plans and create reasonable timelines. Having an advisor available with relevant information whenever needed also helps to instil in the learners the confidence to succeed.

\section{Personal learning/Connectivism}

Hearables are well-placed to support context-aware, adaptive personal learning tailored to each individual learner's personal characteristics and situation. In this way, they can help learners to make their own decisions about what, where, when and how to learn. Learners can take maximum advantage of the continuous connectivity afforded via hearables to achieve their learning objectives, and in the creation of a personal learning network. Immediate access, filtering knowledge domains for the most relevant information distributed on the internet can be facilitated with the help of a PLA.

\section{Conclusion}

So, hearables are coming here to stay both in the wider society and the educational community. Piers Fawkes has commented on one negative effect from using hearables. "Maybe instead of people staring at their screens, they are going to be staring off into the distance. What's it called? The thousand-yard stare" (Glazer, 2014). On a more positive note, perhaps hearables will be helpful in bringing users down to earth, like the slave of Augustus Caesar, who rode with him in his chariot, reminding him that he was not a god, repeatedly whispering in his ear "Memento homo" (Remember you are a man).

\section{References}

Banks, L. (2018, June 13). The complete guide to hearable technology in 2018. Everyday hearing [Blog post]. Retrieved from https://www.everydayhearing.com/hearingtechnology/articles/hearables/

Bragi - https://bragi.com/ 
Bose Hearphones -

https://www.bose.com/en_us/products/wellness/conversation_enhancing_headphones/he arphones.html

Brown, S. (2016, November 3). Hearables: The next big wearable platform. Bald Futurist [Blog post]. Retrieved from http://www.baldfuturist.com/blog/2016/11/1/hearables-the-nextbig-platform

Burrows, P. (2018, August 2). The future is ear: Why "hearables" are finally tech's next big thing. Fast Company [Blog post]. Retrieved from https://www.fastcompany.com/90212065/the-future-is-ear-why-hearables-are-finallytechs-next-big-thing

Computational Thinkers (no date). Hearables No Longer Whispering Wearables. Retrieved from https://www.computationalthinkers.com/hearables-no-longer-whisperingwearables/

Ellis, L. (2018, August 2). Hey, Alexa, Should we bring assistants to campus? These colleges gave them a shot. The Chronicle of Higher Education [Blog post]. Retrieved from https://www.chronicle.com/article/Hey-Alexa-Should-We-Bring/244129

Glazer, J. (2014, April 29). Psst! Wearable devices could make big tech leaps, into your ear. Npr [Blog post]. Retrieved from

https://www.npr.org/sections/alltechconsidered/2014/04/23/306171641/psst-wearabledevices-could-make-big-tech-leaps-into-your-ear

Hunn, N. (2014, April 4). Hearables - the new Wearables. Wearable technologies [Blog post]. Retrieved from http://www.wearable-technologies.com/2014/04/hearables-the-newwearables/

Hunn, N. (2015, February). The Market for Smart Wearable Technology: A Consumer Centric Approach. Retrieved from http://www.nickhunn.com/wpcontent/uploads/downloads/2014/08/The-Market-for-Smart-Wearables.pdf

ITU (2017). ICT Facts and figures 2017. Retrieved from https://www.itu.int/en/ITUD/Statistics/Documents/facts/ICTFactsFigures2017.pdf

Jones, A., Issroff, K., \& Scanlon, E. (2007). Affective factors in learning with mobile devices. In M. Sharples (Ed.), Big issues in mobile learning. Report of a workshop (pp. 15-20.): Nottingham: Learning Sciences Research Institute, University of Nottingham. Retrieved from https://telearn.archives-ouvertes.fr/hal-00190254/document

Lumen Couture (2018, July 9). Hearables: Wearable Tech for your ears. Retrieved from https://www.youtube.com/watch?v=GsBRKr1jQG8

Mehdipour, Y., \& Zerehkafi, H. (2013, June). Mobile learning for education: Benefits and challenges. International Journal of Computational Engineering Research, 03(6). Retrieved from http://www.ijceronline.com/papers/Vol3_issue6/part\%203/P03630930100.pdf 
Mims, C. (2013, August 15). Google is preparing for screenless computers. Quartz [Blog post]. Retrieved from https://qz.com/115304/google-is-preparing-for-screenlesscomputers/

Omnicom Health Group (2017, March). SXSW Interactive Trends. Retrieved from http://www.omnicomhealthgroup.com/pdfs/SXSW 2017 Interactive Trends Paper_FINAL_041717.pdf

Over the Counter Hearing Aid Act, S.670 Stat. (2017). Retrieved from https://www.congress.gov/bill/115th-congress/senate-bill/670?s=7\&r=670

Traynor, R. (2017). Headphones: They have come a long way, baby. Canadian Audiologist, 4(1). Retrieved from http://www.canadianaudiologist.ca/issue/volume-4-issue-12017/column/stories-from-our-past/

Vandergrift, L. (2007). Recent developments in second and foreign language listening comprehension research. Language Teaching, 40(30), 191-210. https://doi.org/10.1017/S0261444807004338

VinciLanguage Teaching, 40(3), pp. 101 - 210. Retrieved from https://doi.org/10.1017/S0261444807004338

Vinci - https://shop.vinci.im/ 